

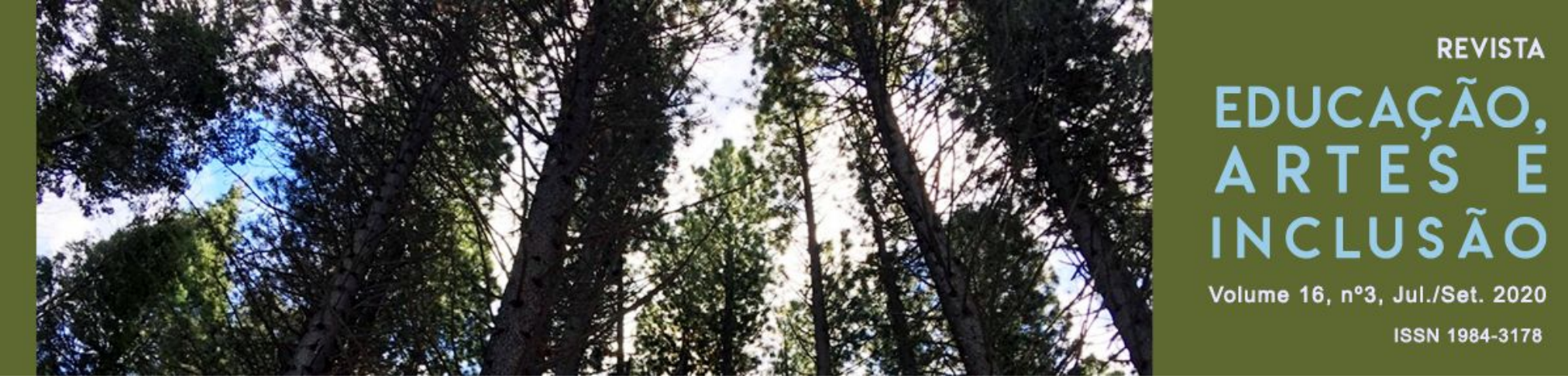

avancemos e também nos incitaram a buscar as Artistas do Sul ${ }^{1}$, aquelas de quem somos herdeiras e daquelas nossas companheiras de jornada. Estivemos com a professora por ocasião do Simpósio Internacional de Gênero, Arte e Memória (VI SIGAM), evento bienal que promovemos na UFPel para difundir e intercambiar ações e pesquisas. A vinda desta pesquisadora a Pelotas era um desejo há muito tempo acalentado, que conseguimos realizar em 2019, apesar de todas as dificuldades enfrentadas, como a falta de apoio por parte das agências de fomento. Situação que atingiu outras equipes e instituições promotoras de eventos acadêmicos sobre gênero, racismo, desigualdade social, homofobia, pluralidades culturais, etc. Temos acompanhado essa postura repressora que o conservadorismo de extrema direita tenta implantar, impondo cortes e descréditos, fazendo recrudescer direitos arduamente conquistados. Como arte/educadoras feministas somos resistência, aproveitamos a oportunidade que o evento proporcionou para não desconvidar ninguém, afinamos o contato com Simioni, conhecemos mais sobre seus métodos e fontes, ao revelar bastidores da pesquisa ela explicita o quanto essas transformações repercutem em nosso cotidiano e confirmam a necessidade de revisão da própria disciplina de história da arte. Os deslocamentos de objetos e a exigência por posturas mais críticas e inclusivas "constituem aqueles ruídos incômodos e necessários para novos reencontros com o passado, os quais assinalam práticas menos excludentes para o futuro" (SIMIONI, 2007).

A participação da pesquisadora espanhola Africa Cabanillas, nos revelou que as dificuldades enfrentadas são da mesma ordem, nesse momento seu grupo investiga a arte feminista espanhola do início do século $X X$. E, tal como aqui, a formação das artistas passa pelas antigas Escolas de Belas Artes, com um ensino acadêmico, defasado e restrito em relação as aulas de modelo vivo e ateliê de

\footnotetext{
${ }^{1}$ As artistas do Sul: experiências lúdicas e educativas, pesquisa em desenvolvimento que investiga as artistas com intenção de desvendar processos criativos, perceber obras e discursos que fundamentam uma coleção de livros ilustrados voltados para o público infantojuvenil.
} 


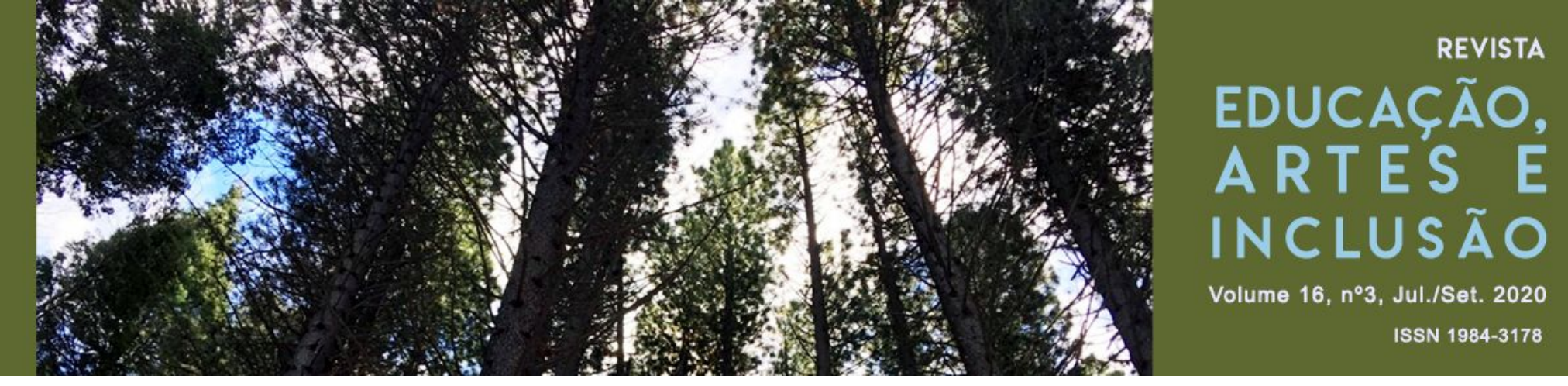

escultura, por outro lado havia um investimento para que seguissem carreira como docentes ou nas artes aplicadas. Algumas enfrentaram as adversidades para se firmarem como profissionais, porém a história não computou suas trajetórias. $O$ problema comum a todas nós pesquisadoras diz respeito a esse silenciamento e ao desaparecimento de suas obras. De forma descuidada e ou intencional, ficamos sem as provas de que, para além de serem as modelos, filhas, irmãs, esposas ou amantes dos artistas, as mulheres foram artistas. Para essa perda de autoras e obras a crítica feminista formulou postulados que, lamentavelmente, ainda seguem vigentes.

O VI SIGAM constituiu um momento de reunião e união. Estivemos juntas para debater, aprender, trocar e, sobretudo, homenagear mulheres artistas, professoras e pesquisadoras, que impactaram nossa formação. lara Cava, Inah Costa, Arlinda Nunes, Assunção Gonçalves, Odette Dias, Therezinha Röhrig e Dona Conceição (Figura 1), são algumas que se fizeram presentes como temas de palestras, acompanhamos as trajetórias que vão se mesclando a outras e permanecem ressoando. Com arte e com afeto elas foram apresentadas pelas colegas, amigos e amigas, por aqueles e aquelas que foram seus alunos e alunas, filhas e netas, que fizeram questão de nos trazer seus depoimentos e vivências, destacando a dimensão feminina e feminista implicada na obra e na vida dessas pioneiras. 

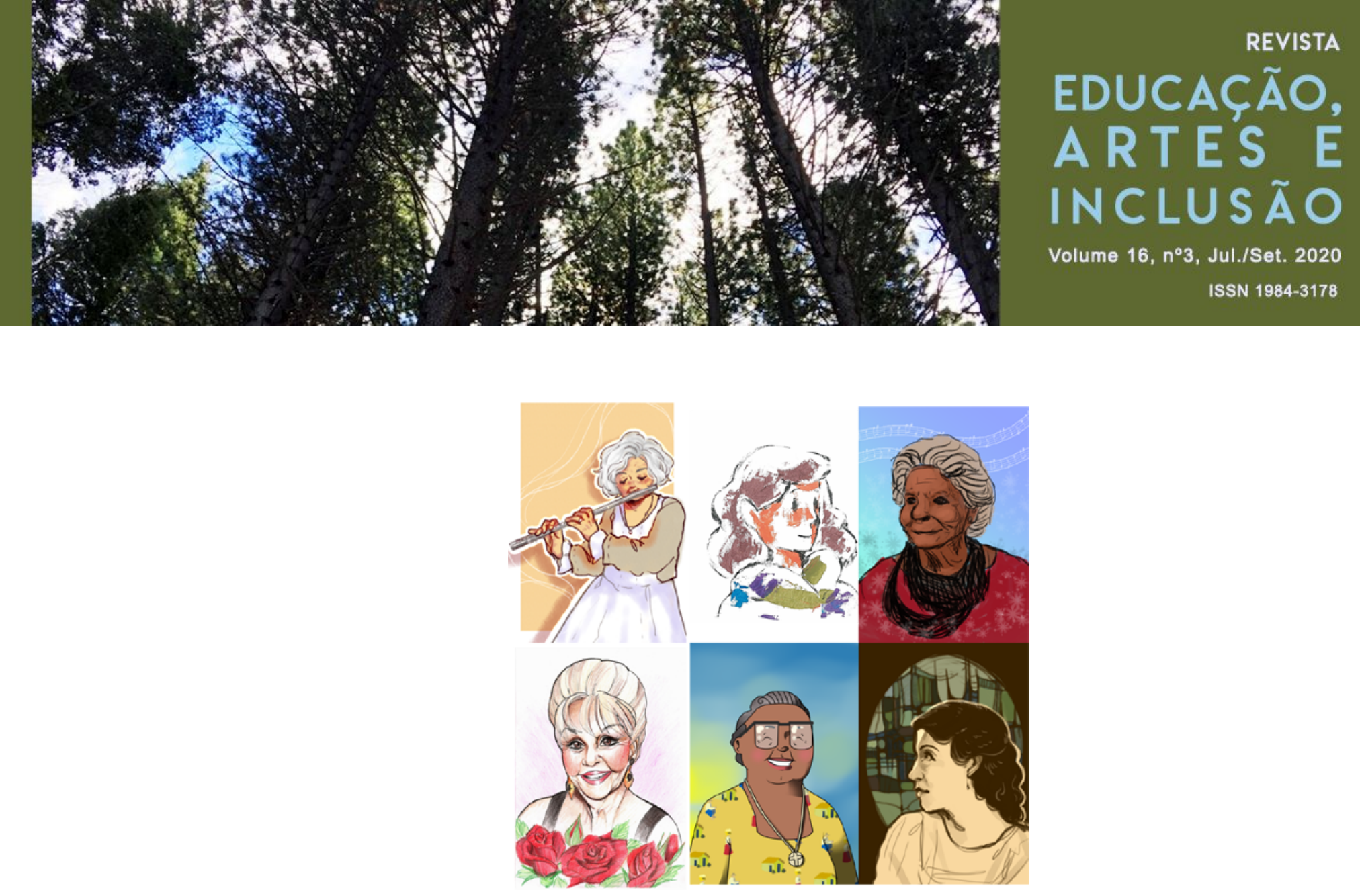

Figura 1: llustrações de Odette Dias, Arlinda Nunes, Dona Conceição, Therezinha Röhrig, Assunção Gonçalves e Inah Costa. Fonte: Grupo de Pesquisa

Nossa mobilização tem sido constante, em prol da educação, da arte, das mulheres artistas, da diversidade e da liberdade de expressão. Além do simpósio, temos experimentado ações integradas que reúnem diferentes participantes, em sala de aula, museus, centros de convivência, associação de moradores. Oferecemos oficinas, rodas de conversa, ações performáticas, mostras, encontros com artistas, educadoras e líderes comunitárias com interesse em dar a ver protagonismos, ouvir as histórias, reconhecer processos e projetos, sejam transgressores, radicais ou "discretas ousadias", como se refere Simioni, tudo importa.

A historiadora francesa Michelle Perrot (1990) pertence ao grupo de pensadoras recorrentes, sua contribuição é fundamental para a história das mulheres e, demais excluídos da história. A autora atenta para o viés ideológico e político que o próprio trabalho impõe, trazendo o questionamento acerca das dificuldades que envolvem a pesquisa e o registro sobre a produção das mulheres, de modo geral. Como causa para a invisibilidade da mulher na história, Perrot 


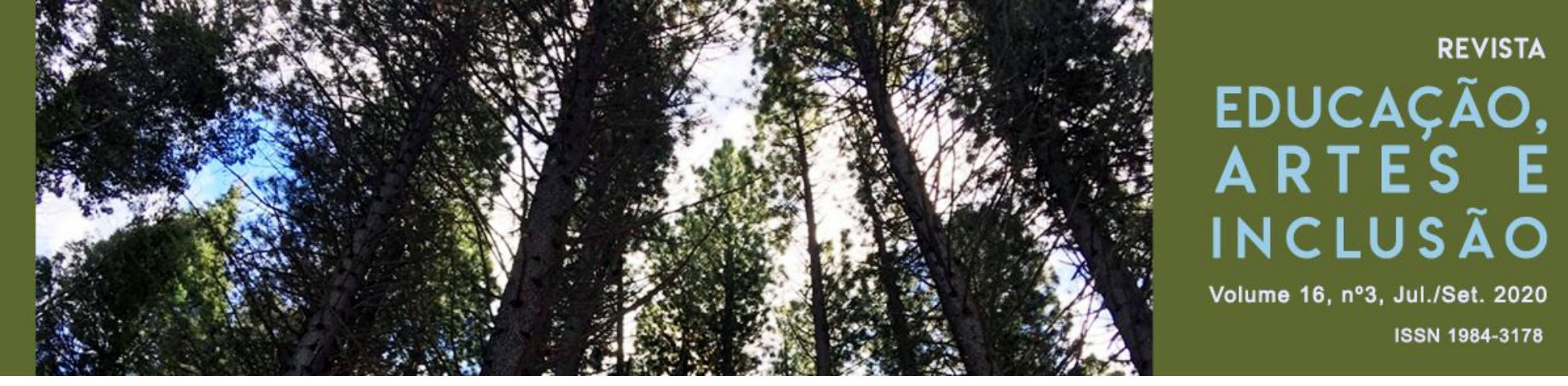

aponta para a ausência das mulheres no espaço público (lembrando que elas sempre foram limitadas ao ambiente doméstico) e identifica o silêncio das fontes, ocasionado pela escassa quantidade de material produzido - seja pelo acesso aos meios de produção, seja pela aceitação de uma condição de incapacidade dessas mulheres subjugadas a outros afazeres.

Contar, ou recontar, a história das mulheres exige fundar metodologias, estabelecer abordagens relacionais e culturais, construir e desconstruir conceitos, como a própria noção de gênero e da universalidade da mulher. É preciso valorizar experiências, diferenças, lugares de fala, considerar interconexões entre gênero, raça e classe. A teoria feminista tem constituído uma alternativa válida para compreender discursos e manifestações artísticas entabuladas por ativismos e dinâmicas culturais.

A revisão do pensamento feminista empreendida por Heloísa Buarque de Hollanda cumpre o objetivo de reunir as contribuições de intelectuais e ativistas, responsáveis pela consolidação dos estudos feministas e de gênero como campo legítimo do conhecimento. Estivemos no lançamento das coletâneas Pensamento Feminista Brasileiro: formação e contexto e, Pensamento Feminista: conceitos fundamentais, organizadas pela pesquisadora em 2019, obras que já despontam como referência para a pesquisa atual e para as novas gerações. Nos encantamos com a energia e curiosidade irrequieta dessa mulher, Helô versão 8.0, como ela mesma proclama. Sua produção bibliográfica também é celebração, é para festejar sua trajetória intelectual, seus encontros teóricos, experimentações político-pedagógicas e seu comprometimento com o feminismo.

Feminista da terceira onda, Hollanda soube perceber que um novo feminismo ganhava as ruas, com estratégias próprias, baseadas em experiências pessoais e coletivas, que se organizam em rede e usam a arte como plataforma para as reivindicações. A quarta onda é delineada e experimentada em escrita polifônica, em outra obra Explosão Feminista: arte, cultura, política e universidade, onde abre 


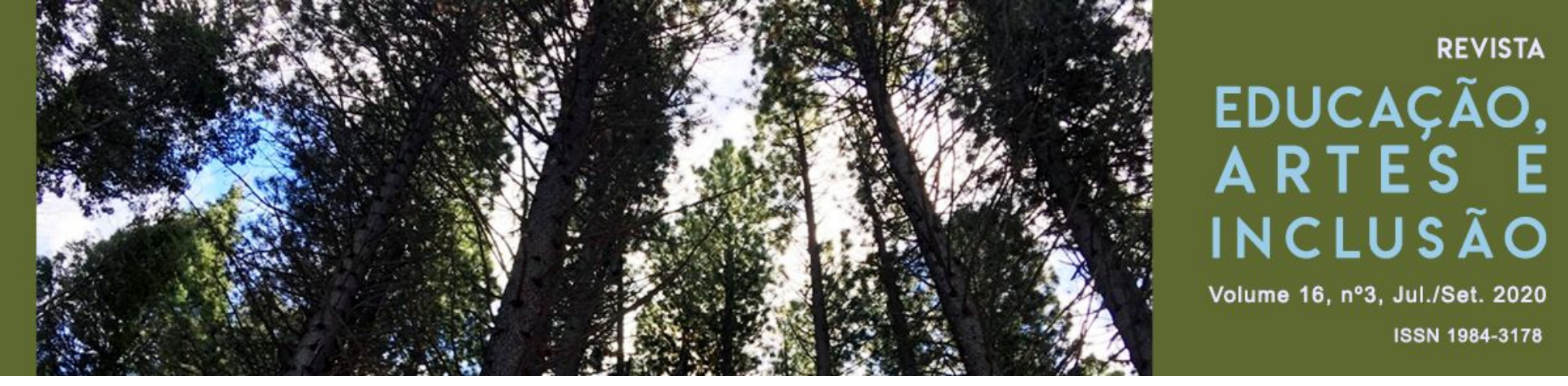

espaço para examinar os feminismos da diferença. Feminismo Negro, Feminismo Indígena, Feminismo Decolonial, Feminismo do Sul são ramificações que atestam a complexidade que incide sobre os estudos de gênero, atentando para outros eixos de opressão determinantes em nossa sociedade.

\section{CONSTRUINDO PONTES}

\section{Hay tantissimas fronteras \\ que dividen a la gente, \\ pero por cada frontera \\ existe también un ponte.}

(Gina Valdés, HOLLANDA, 2019, p.33)1

Se na arte a força de uma expressão das mulheres está sendo evidenciada com grande esforço, precisamos, ao mesmo tempo, apontar que outras vozes precisam ter espaço, como as dos indígenas, dos negros e demais comunidades étnicas pouco privilegiadas pela história. Desse modo, repensar a formação em artes para professores e artistas, no Brasil, deve ser um exercício norteado pela elaboração de currículos que contemplem: autoras mulheres; pensadores e pensadoras negras e indígenas, e, ainda, expressões intelectuais, culturais e artísticas latino-americanas. Torna-se, assim, possível uma epistemologia que fale de valores e saberes; que trate do que é nosso e possa propiciar uma visão de mundo que envolva corpos diferentes (pardos, negros, cafuzos, mestiços etc.), que muitas vezes foram marginalizados e vistos como inapropriados.

A pedagogia decolonial é pedagogia de luta e de autonomia. Ela traz elementos de alguns autores, tais como, Franz Fanon, Silvia Winter, Nelson Maldonado-Torres, Paulo Freire, Catherine Walsh, Pedro Gomez, Walter Mignolo, Adolfo Achinte.

Com base nessas referências, Pedro Pablo Goméz (2018), artista, colombiano e teórico da arte destaca-se como um dos autores que tem colocado a 


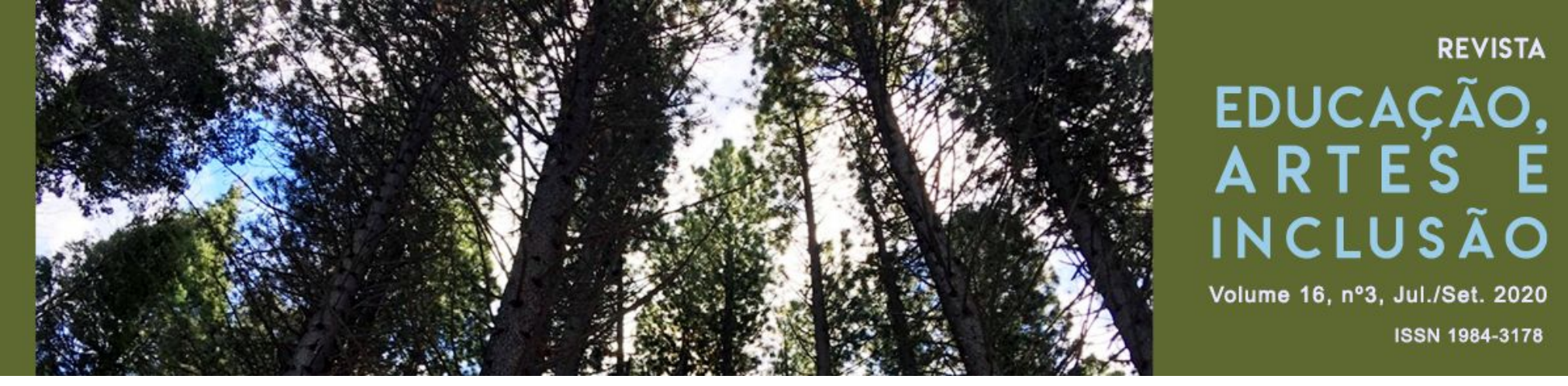

âmbito, os estudos artísticos são o resultado de práticas epistêmicas, estéticas e políticas. Essas práticas estão eticamente comprometidas com as necessidades de transformação social e com as condições de vida das pessoas.

É um espaço que vem tomando forma, desde 2009, como efeito de uma série de encontros possíveis, de caminhos cruzados e de impulsos in-disciplinares, epistêmicos e estéticos. A decolonidade se agencia a partir da universidade, mas suas práticas não estão confinadas nela, pois seus espaços de intervenção estão dentro e fora dela, ou seja, em todos os lugares onde a colonialidade: afeta os corpos; desumaniza as pessoas; controla o poder e, determina o saber, destruindo a natureza e a vida (GOMEZ, 2018). Os estudos decoloniais têm caráter fronteiriço e em construção permanente. Neles, as práticas artísticas, modos de fazer e estéticas acadêmicas se encontram com diversos outros saberes e práticas aiestheticas - são memórias e trajetórias próprias. Esse conjunto de conhecimentos é capaz de abordar problemas que escapam das estreitas perspectivas disciplinares e do seu euro-norte-americano-centrismo colonial.

O resultado dessa união de esforços é uma pluralidade de saberes localizados, colaborativos e comprometidos com uma expressa pretensão de incidência social a partir das bases. A pretensão de criar conhecimentos sensíveis que não reproduzam a colonialidade implica em maneiras outras de pensar a epistemologia, a pedagogia, a metodologia, a estética, a política, a economia e o saber em geral. Para isso, são necessárias ferramentas pedagógicas também distintas que nos ajudem a desaprender nossos habituais modos de conhecer e agir para reaprender e criar outros conhecimentos de outros modos.

Ana Mae Barbosa é unanimidade quando se trata de reconhecer a capacidade cognitiva e inclusiva da arte. A pioneira da arte/educação no Brasil permanece atenta para as problemáticas e desafios que incidem sobre o processo 


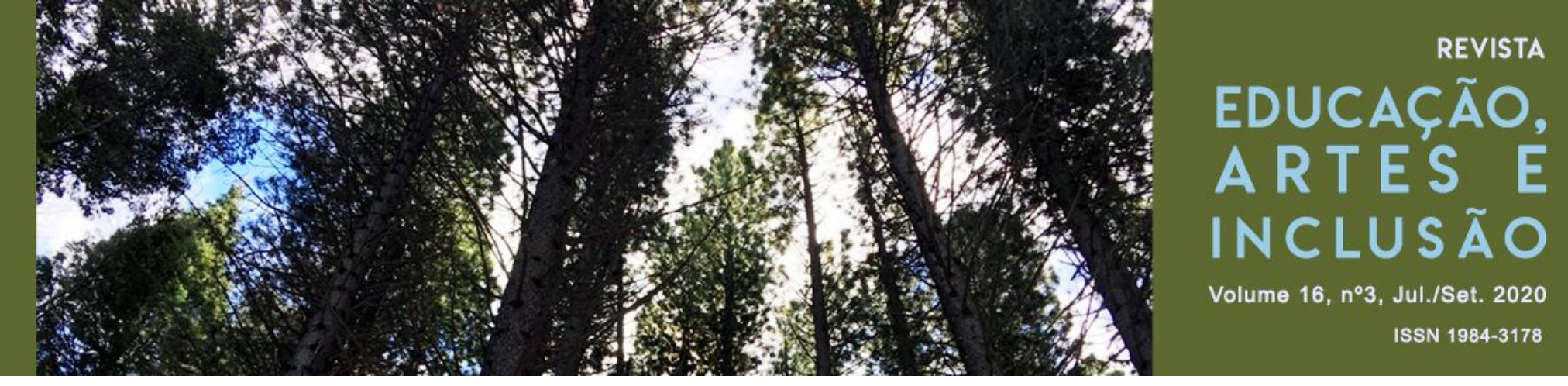

educativo contemporâneo. A questão da diversidade não só deve adentrar os currículos como precisa ser a matriz geradora.

Entretanto, mais que um mero tema de estudo de todas as disciplinas, as questões relativas a multiculturalidade só serão resolvidas pela flexibilização de atitudes e valores. Por outro lado, não se trata de um tema transversal, mas básico para uma sociedade que se configure como democrática (BARBOSA,1998, p.89).

O apontamento foi feito há mais de vinte anos, quando o MEC lançou os Parâmetros Curriculares Nacionais (1997), mencionando a diversidade cultural e a sexualidade como temas possíveis de serem abordados nas aulas de arte. Impressiona a defasagem e o retrocesso que sucedeu desde então. Os temas foram abolidos e também as artes dos currículos. Em 2018, arte deixou de ser componente obrigatória para o Ensino Médio e, as corporações pressionam para que seja banida das escolas públicas. A liberdade que a arte aciona se opõe ao controle que o autoritarismo exige. Aliás, o desmonte institucional da cultura pelo atual governo extinguiu o Ministério, que passou a ser uma pasta, mas não ligada ao Ministério da Educação e sim ao Turismo. Seus gestores têm nos impingido perdas e vexames internacionais, como a citação ao discurso do nazista Goebbels, em edital para premiar uma arte "heroica e nacional".

Em movimento de resistência Ana Mae Barbosa organiza e convoca os representantes educacionais para o Congresso de Ensino/Aprendizagem das Artes na América Latina: colonialismo e questões de gênero, em abril de 2019, em São Paulo. O evento teve como missão intensificar a conscientização da sujeição à colonização cultural e o combate da desqualificação da arte no sistema educacional. A dinâmica apostou no debate dos temas previamente estudados pelos participantes, para tanto a equipe disponibilizou livros, artigos e documentários. Cabe esclarecer que alguns dos autores insurgentes que selecionamos para esse trabalho constavam na listagem enviada. 


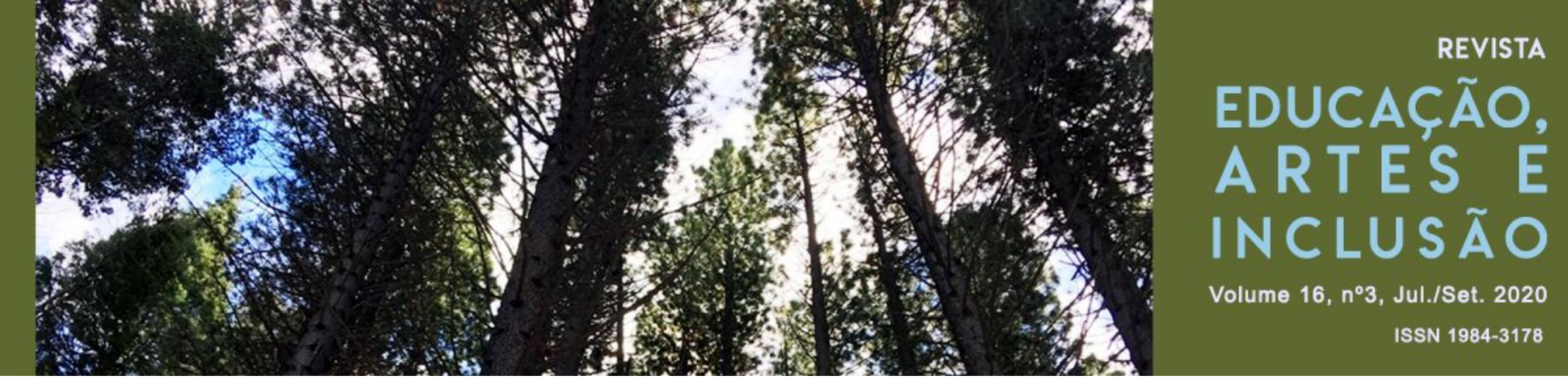

no enfrentamento das dificuldades, a generosidade na partilha de saberes, a curiosidade e bravura para experimentar o novo, romper com tradições e serem exemplos para nós que as sucedemos (Figura 2).

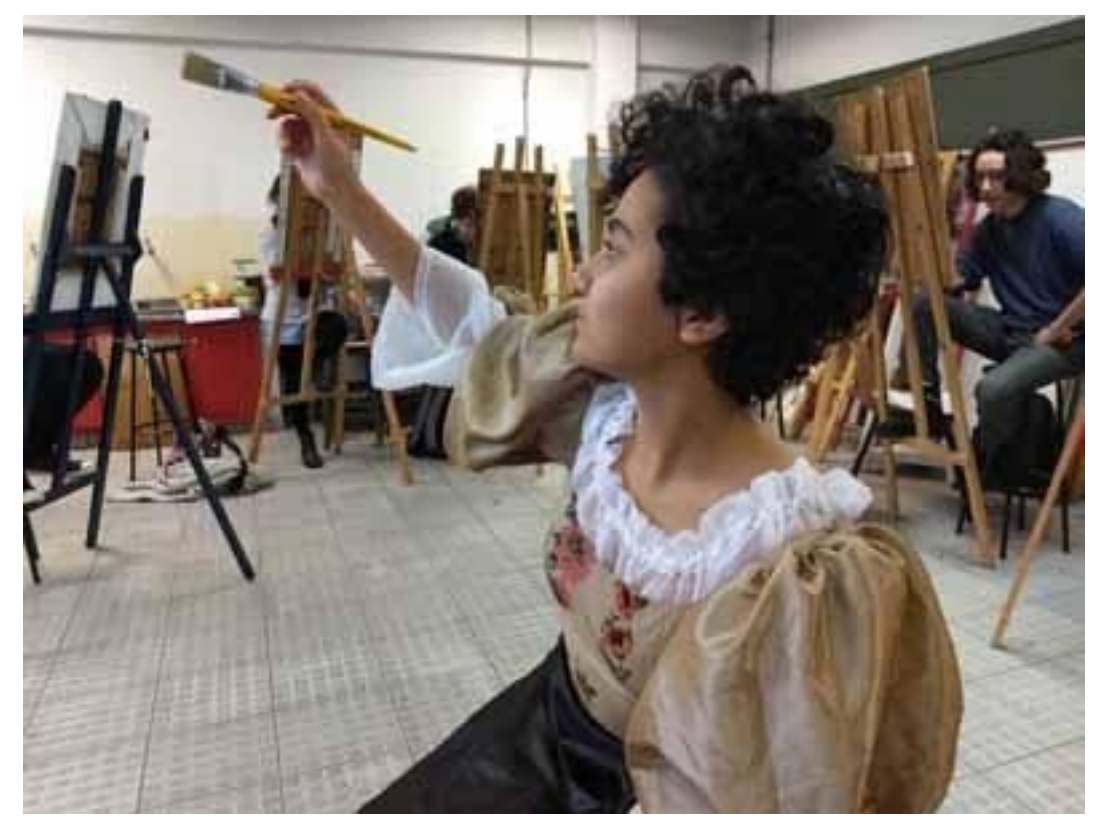

Figura 2: Aluna caracterizada como Artemísia Gentileschi em aula de desenho. Fonte: Autoras.

Algumas proposições envolvem deliberadamente o ensino, a pesquisa e extensão, de forma que a experiência artística reverbere e evidencie relações e discursos, proporcionando diálogo entre diferentes, para gestar empatias, promover atitudes de empoderamento e gestar alianças.

É essencial dar a conhecer, valorar entornos e repertórios, propor experiências de decodificação e atualização dos signos produzidos no âmbito da cultura. Abrimos espaço para os temas emergentes, para que as inquietações possam ser divididas. Quebramos regras e propomos a exceção, a transgressão como conteúdo. O episódio Queermuseu, arte afro-brasileira, o sincretismo religioso, o ativismo de maio de 2019, adentraram a sala de aula, o ateliê de desenho e de gravura, o espaço do museu e ganharam a rua (Figura 3). Para que uns e outros 


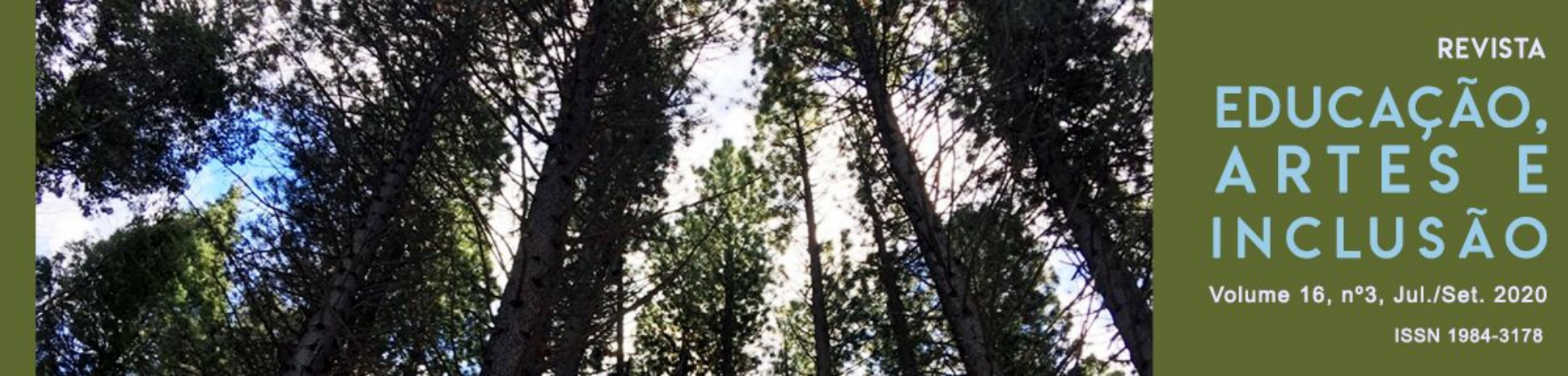

possam perceber e reconhecer que representações, apresentações, manifestações e situações desencadeiam significados e sentidos que são atravessados pelas relações de poder. As ações têm possibilitado estabelecer conexões que extrapolam temporalidades, culturas e geografias, conjugam poesia, didatismo e ativismo político

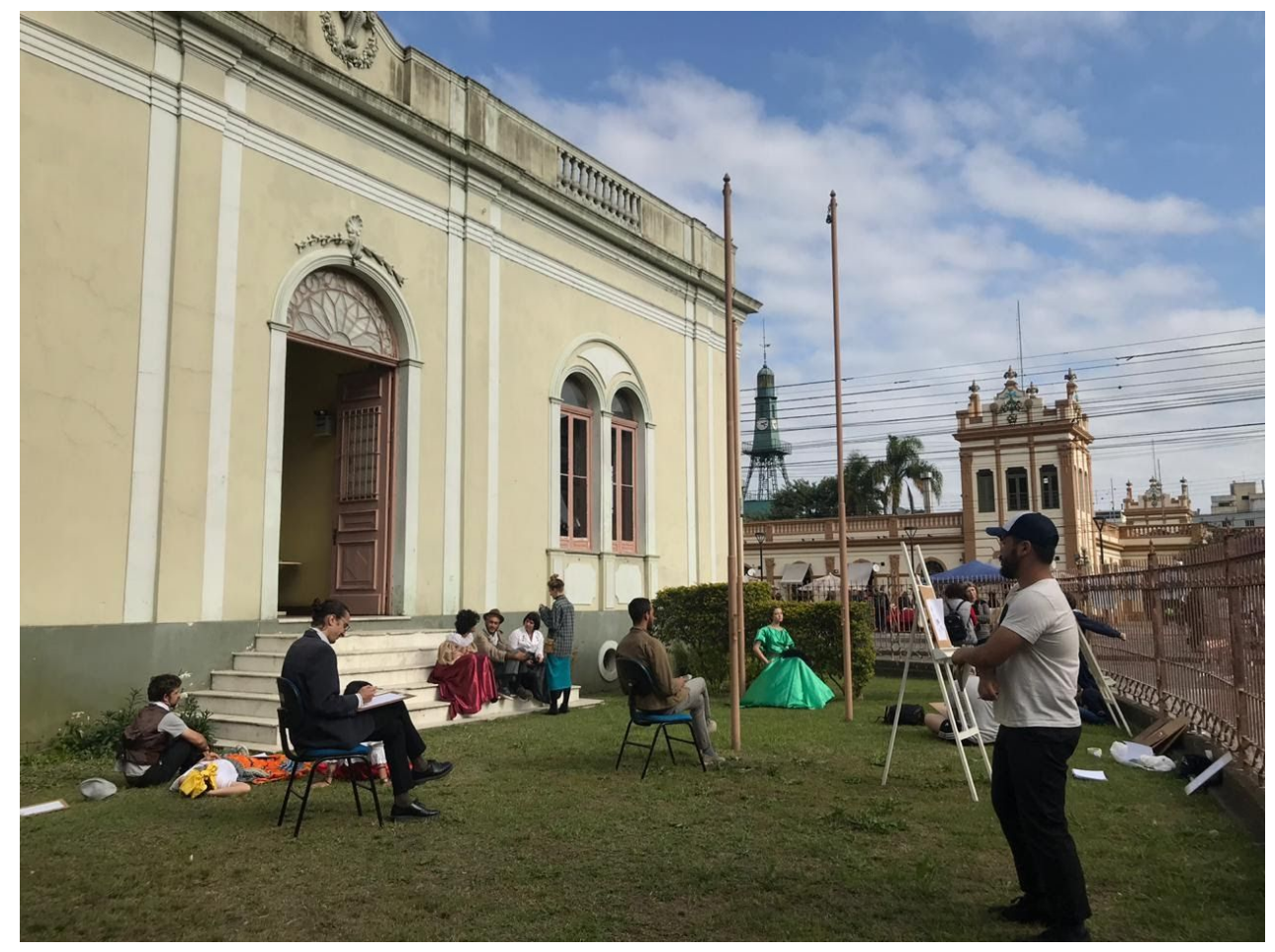

Figura 3: Ação Performática no MALG, Pelotas. Fonte: Autoras.

A rede de pensadores insurgentes se completa com Catherine Walsh (2017), que como nós admira um educador recorrente Paulo Freire. A pedagoga da decolonialidade, como é conhecida, aposta nos estudos culturais como projeto intercultural, inter-epistêmico e de orientação decolonial, para enfrentar desafios urgentes dentro e fora da universidade. Para Walsh, os estudos culturais são campo de formação, articulação e encontro entre disciplinas, projetos intelectuais, políticos e éticos que proveem de distintos lugares históricos e epistemológicos e que têm 


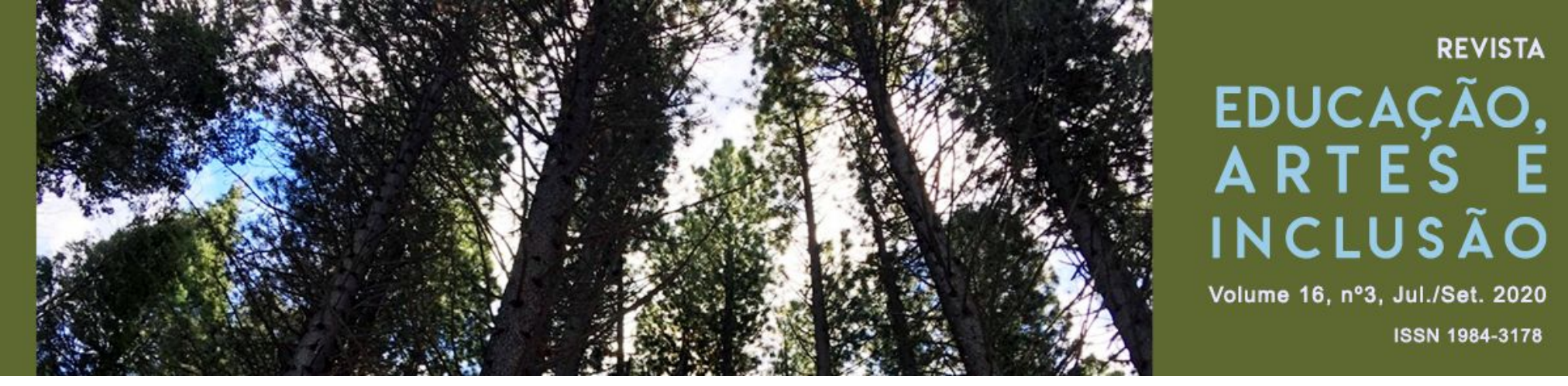

Las pedagogías pensadas así no son externas a las realidades, subjetividades e historias vividas de los pueblos y la gente, sino parte integral de sus combates y perseverancias o persistencias, de sus luchas de concientización, afirmación y desalienación, y de sus bregas - ante la negación de su humanidad - de ser y hacerse humano. Es en este sentido y frente a estas condiciones y posibilidades vividas que propongo el enlace de lo pedagógico y lo decolonial. (WALSH, 2017, p. 24)

Podemos nos perguntar qual o motivo de, atualmente, o pensamento de Freire ser considerado ameaçador? Parece algo muito forte e correto o enunciado de um educador que aponta para valores humanos, éticos, e para a necessidade de valorizar a pessoa em sua humanidade. Um professor que ensina o que é ensinar com dignidade, humildade, respeito, que vê o outro e quer aprender com o que esta vida tem para ensinar. Um pedagogo que sabe que para ensinar é preciso saber ouvir, saber enxergar o mundo, o contexto, saber agir e ser coerente:

Qualquer discriminação é imoral e lutar contra ela é um dever por mais que se reconheça a força dos condicionamentos a enfrentar. A boniteza de ser gente se acha, entre outras coisas, nessa possibilidade e nesse dever de brigar. Saber que devo respeito à autonomia e à identidade do educando exige de mim uma prática em tudo coerente com este saber. (FREIRE, 1996, p.25)

Freire entendia que educar é um exercício de educar a si e ao outro, e é um ato político, sendo que a educação não pode se limitar ao espaço formal ou institucional, mas inclui os contextos sociais, políticos e existenciais. E afirma que "além de um ato de conhecimento, a educação é também um ato político. É por isso que não há pedagogia neutra" (FREIRE, 1986, p. 17). Para ele, a aprendizagem necessita de criatividade, e para sermos criativos precisamos ser livres. Assim, a sala de aula deve ser um espaço de liberdade e de libertação.

Assim, inspirada em Freire, Walsh propõe semear a esperança (2017), não no sentido de espera, mas de pequenas ações, semeando pontinhos de esperança. Um movimento de resistência, insistência no que é humano, no que é digno, para que 


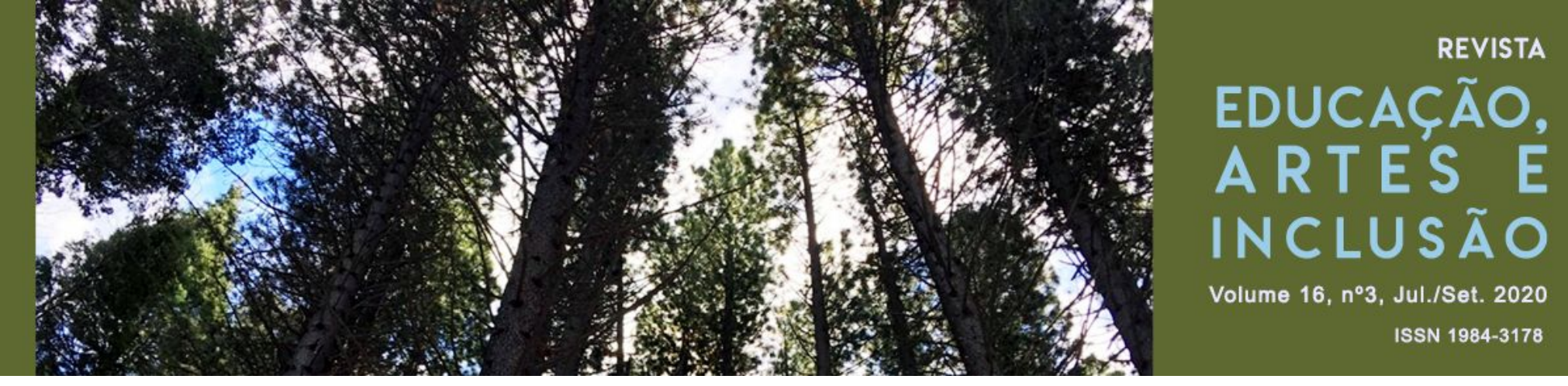

não nos embruteçamos, esquecendo de olhar para o outro como o que deve ter tantos direitos e possibilidades quanto nós.

Outro autor que inspira Walsh é Franz Fanon, um dos primeiros a refletir sobre uma epistemologia que compreenda as questões decoloniais, os corpos colonizados, a partir das condições raciais, das condições existenciais e ontológicas circunscritas por condições de um corpo, que não é sempre o branco. De certa forma, pensar o conhecimento a partir de um lugar existencial, precisa considerar as questões dos diferentes lugares de enunciação, "lugar de fala", como se diz hoje, e este lugar começa no próprio corpo. Para ele, o que proporciona a desumanização é a condição colonial, e a humanização não se sustenta apenas com o conhecimento. O colonialismo produz marcas no corpo colonial, segundo Fanon: "en el cuerpo físico, político y discursivo, lo hace desde esta especie de evidencia retórico-política que enuncia y denuncia una sujeción, la colonial, cuyo lugar y temporalidad, por efectos de esta misma enunciación, han sido dislocados (Fanon apud DE OTO, 2006, p.2). O corpo colonizado precisa ser um corpo político e de ação, um corpo histórico, social, cultural, é o que propõem estes autores.

Walsh nos apresenta que, tanto em Fanon como em Freire, o processo de humanização precisa ser consciente de sua possibilidade, e estar consciente das estruturas sociais que podem contrapô-la. A humanização individual depende de um processo de humanização social. (WALSH, 2017, p. 48).

\section{NO LIMIAR DAS MUDANÇAS}

A sociedade atual tem padecido de uma crise de humanidade que se tem revelado nas práticas conservadoras, de apagamento e violência social, de retrocesso nas políticas públicas para a educação, a ponto de se pensar se o Estado tem condições de manter o compromisso de garantir liberdade e direitos básicos a todos nós. A pandemia do COVID 19, que se espalha rapidamente e atinge o mundo 


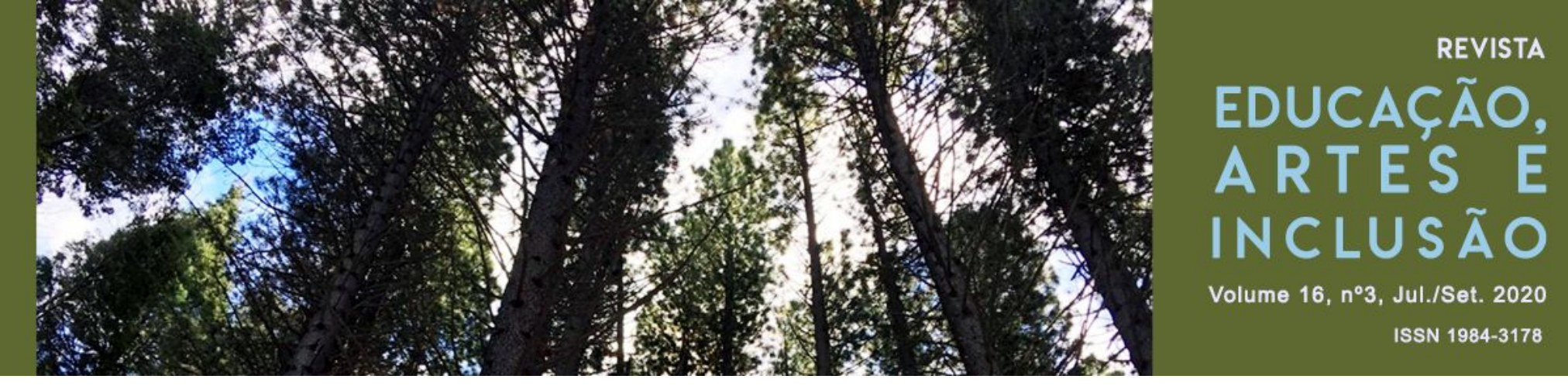

Escribo gritando. Gritando escribo. Lxs que me conocen saben que nunca -o muy rara vez- grito; mi manera de expresar los sentimientos de frustración, indignación, rabia, dolor y horror es otra. No obstante, ahora no puedo contener este chillido que nace desde muy adentro y que sale por los poros y orificios de mi cuerpo como estruendo. Los órganos en su conjunto y liderado por el alma y el corazón, gritan ¡NO!, gritan ¡DIGNIDAD!, y gritan ¡VIDA! Mi grito es producto y reflejo de la acumulación de un sentir. (WALSH, 2017, p. 66)

Aos gritos resistimos, transgredimos, expomos diferenças, ouvimos o outro, recusamos posições dogmáticas. Assim temos feito em sala de aula, com os grupos, propondo trocas de papéis, para que uns experimentem estar no lugar do outro, sendo aprendizes e formadores. Compreender que a educação é um processo inclusivo é fundamental para almejar uma formação que avance sobre premissas instituídas, que ultrapasse distâncias e contemple a diversidade, para de fato ser emancipatória e empoderadora.

Temos nos perguntado como seguir em frente, depois desta realidade que nos deslocou para um outro cotidiano, de isolamento, de encontro compulsório com a dor, com a morte, como vai ser? Como superar as desigualdades e a falta de uma política pública responsável e humanitária, que atenda as populações vulneráveis? Pois é sobre os excluídos do mundo, que o impacto da pandemia incide com maior perversidade. Para aqueles que moram nas favelas, periferias, em campo de refugiados, em situação de rua, indígenas, negros pobres e idosos, isolamento social tem outro significado, inclusive não se aplica como medida para conter o contágio.

Num país de extrema desigualdade como o nosso, temos os sem renda nenhuma, ou que dispõem de uma renda mínima proveniente da prestação de serviços básicos e essenciais: porteiros, agentes de limpeza, de segurança, entregadores, motoristas, atendentes, e ainda, temos os trabalhadores informais, os 


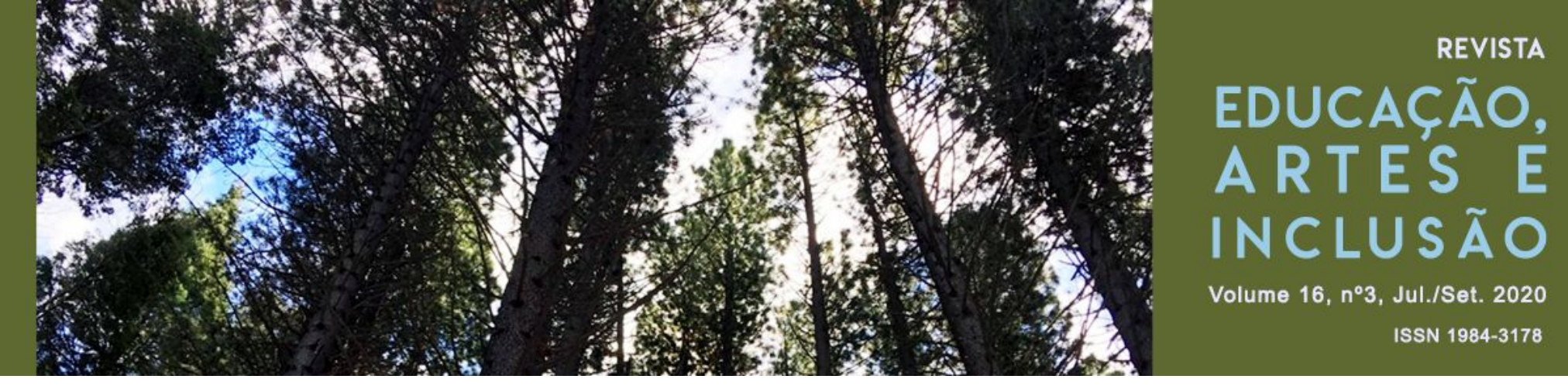

sem emprego que se reinventaram para seguir vivendo. Esses grupos enfrentam a pandemia com uma máscara doada. Que lição podemos tirar disso tudo?

Achinte identifica o movimento Re-existência, como a capacidade que as comunidades silenciadas e excluídas, têm para criar novas formas e dispositivos, que lhes permitam enfrentar as adversidades e confrontar o pensamento hegemônico.

\begin{abstract}
A re-existencia aponta a descentrar as lógicas estabelecidas para buscar nas profundidades das culturas - neste caso indígenas e afrodescendentes - as chaves de formas organizadas de produção, de alimentos, rituais e estéticas que permitam dignificar a vida e reinventá-la para permanecer transformando-se. A re-existência se refere ao que o líder comunitário Héctor Berón "Pájaro", assassinado em 1986, no centro do Valle del Cauca, Colombia, afirmou: "O que vamos inventar hoje para seguir vivendo?" (ACHINTE, Adolfo, 2009, p.456)
\end{abstract}

Uma outra percepção de si e de mundo se instala após a crise, esperamos que prevaleça uma atitude mais responsável, com maior engajamento e colaboração entre todos, que a solidariedade seja uma estratégia universal. Que as estéticas de re-existência, estéticas do ato criativo assumam o protagonismo e que sobrevenha a estética como aiesthesis, a partir do afeto, compreendendo o amplo mundo do sensível, a vida como um todo interligado.

Experimentamos a (RE)EXISTÊNCIA como mobilização na greve de 2016, contra a emenda que limita os gastos com educação e a medida provisória que instaurou a reforma no ensino médio. Foram muitas ações coletivas envolvendo a comunidade para explicitar que recursos destinados à educação são investimento, possibilidade de futuro (Figura 4). 

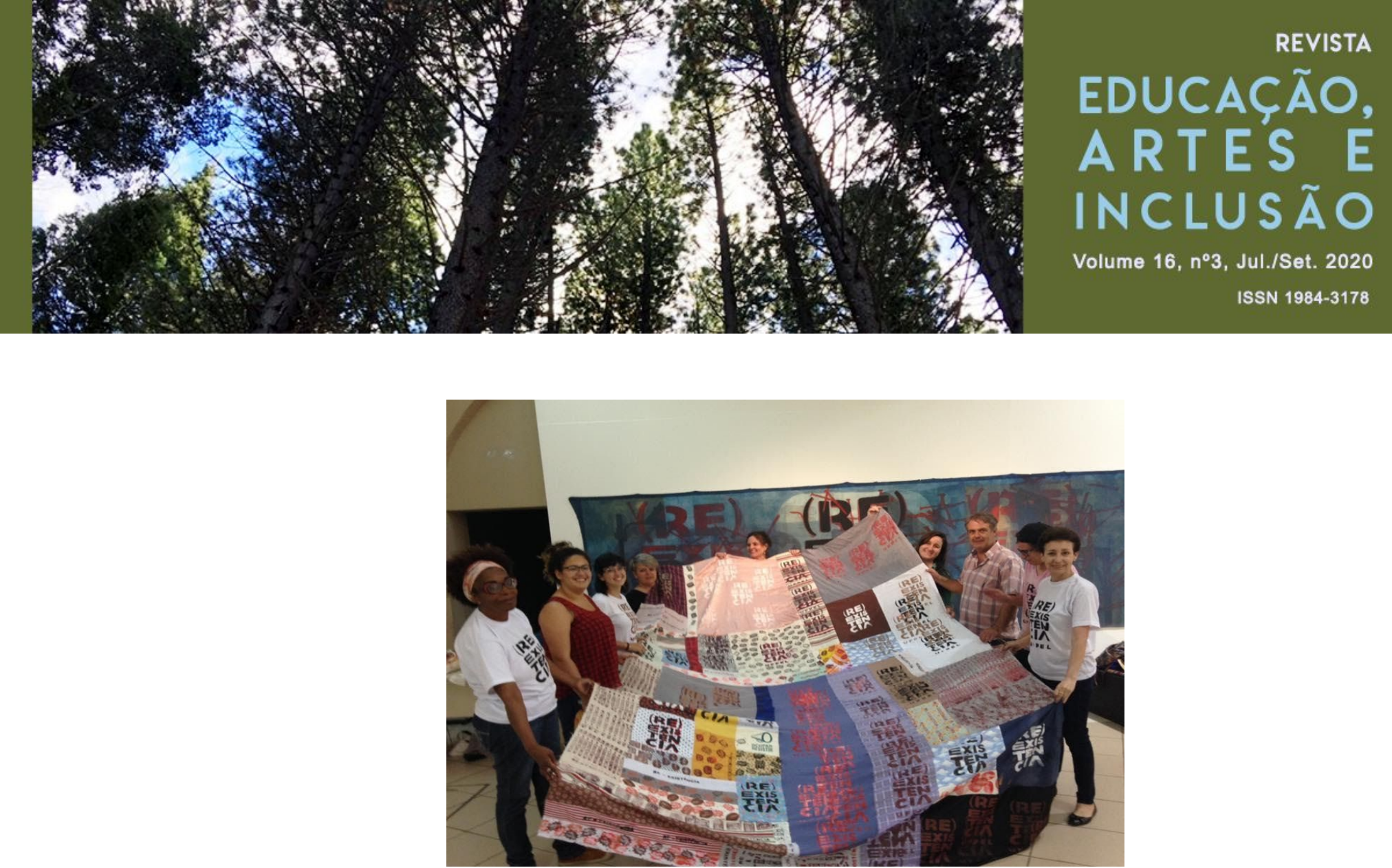

Figura 4: Ação Coletiva (RE)EXISTÊNCIA, Pelotas, 2016. Fonte: Autoras.

Precisamos ser ativadores de novos espaços de criação e estimuladores da educação para que surjam sempre novos docentes. Também é preciso sermos capazes de sensibilizar para os temas atuais e urgentes: violência de gênero, racismo, desigualdade social, multiculturalidade, meio ambiente. É com a pluralidade, compartilhando conhecimento que podemos recuperar o humanismo que nos forja sob o princípio da igualdade e respeito aos direitos humanos. As ações propositivas que experimentamos instauram rupturas porque implicam em outros modos de ver, para olhar a si mesmo e perceber o outro. É preciso aprender a vermo-nos como sociedade, pertencentes a um mesmo mundo e compartilhando das mesmas necessidades de vida e de felicidade. Em tempos de crise e obscuridade é preciso trazer a arte, acionando seu viés mais político, pelo desassossego que provoca, abalando convicções para fazer aflorar pensamento crítico e fruição em perspectiva ampliada, inclusiva e cidadã. Sejamos (RE)EXISTÊNCIA como afirmam nossos autores referentes e insurgentes (Figura 5). 


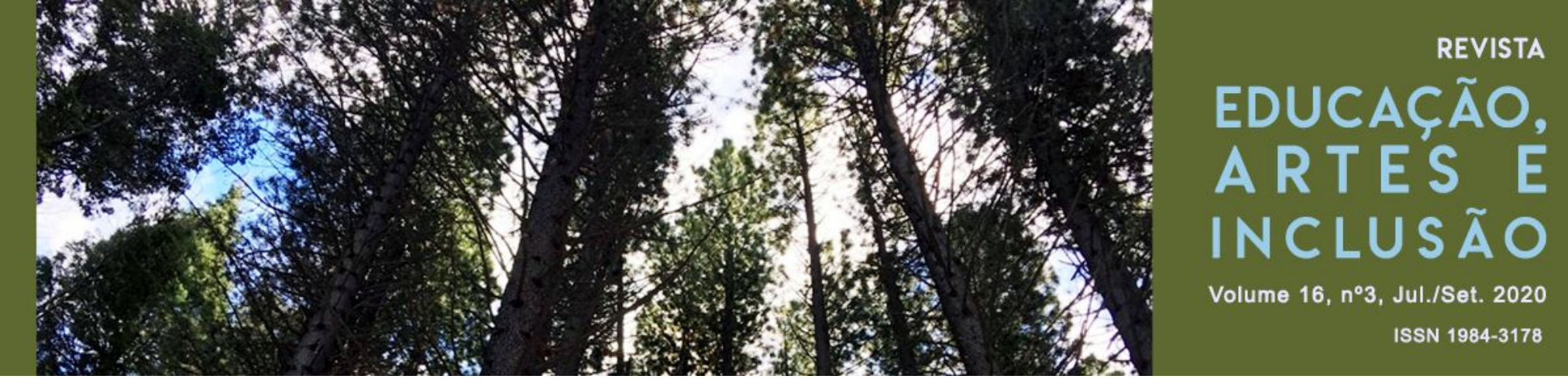

FREIRE, Paulo. Pedagogia da autonomia: saberes necessários à prática educativa. Rio de Janeiro: Paz e Terra,1996.

El grito manso. México: Siglo XXI, 2003.

Pedagogía de la esperanza. México: Siglo XXI, 1993.

GOMEZ, Pedro Pablo; WALSH, Catherine; LAMBULEY, Ricardo. Aprender,crear, sanar: estudios artísticos en perspectiva decolonial. Bogotá, 2018.

HOLLANDA, Heloisa Buarque de. Explosão feminista: arte, cultura, política e universidade. São Paulo: Cia das Letras, 2018.

HOLLANDA, Heloisa Buarque de. (org.). Pensamento feminista: conceitos fundamentais. Rio de Janeiro: Bazar do Tempo, 2019.

Pensamento feminista brasileiro: formação e contexto. Rio de Janeiro: Bazar do Tempo, 2019.

MALDONADO-TORRES, N. El arte como territorio de re-existencia: una aproximación decolonial. Iberoamérica social: revista-red de estudiossocialesVIII, 2017, p. 26-28.

Disponível

em https://iberoamericasocial.com/arte-territorio-re-existencia-una-aproximacion-decolonial.

Acesso 03 dez. 2019.

MIGNOLO, Walter; GOMEZ, Pedro Pablo. Estéticas y OpcionDecolonial. 2012.Disponível em:https://pt.scribd.com/doc/158826406/Esteticas-y-Opcion-Decolonial-Walter-Mignolo-y-Pe dro-Pablo-Gomez-Editores. Acesso 03 dez. 2019.

PASTORINO, Magalí. Marcas estéticas de la resistencia: el arte desde las prácticas docentes a la salida de la dictadura uruguaya. In: Ibero America Social, mai. 2017. Disponível

em:https://iberoamericasocial.com/marcas-esteticas-la-resistencia-arte-desde-las-practicas-d ocentes-la-salida-la-dictadura-uruguaya/. Acesso 03 dez.

PERROT, Michelle. Minha história das mulheres. Tradução: Angela M. S. Corrêa. 1. Edição, São Paulo: Contexto, 2008. 190 p.

SIMIONI, Ana Paula C. Profissão Artista - pintoras e escultoras acadêmicas brasileiras. São Paulo: EDUSP/APESP, 2008

As mulheres artistas e os silêncios da história: a história da arte e suas exclusões. In: Labrys, études féministes/ estudos feministas, janeiro / junho 2007. Disponível em: https://www.labrys.net.br/labrys11/ecrivaines/anapaula.htm/ acesso $10 \mathrm{abr}$. 
